\title{
Outcomes of non-infectious Paediatric uveitis in the era of biologic therapy
}

\author{
Megan Cann', Athimalaipet V. Ramanan ${ }^{1,2^{*}+}$, Andrew Crawford ${ }^{3,4}$, Andrew D. Dick ${ }^{1,2,5,6}$, Sarah L. N. Clarke ${ }^{1,4}$, \\ Fatima Rashed ${ }^{2}$ and Catherine M. Guly ${ }^{1+}$
}

\begin{abstract}
Background: There is a paucity of data on the ocular outcomes in paediatric non-infectious uveitis since the introduction of the biologic agents. The purpose of this study was to outline the clinical characteristics of children with non-infectious uveitis and determine the visual outcomes and ocular complication rates in the modern era.

Methods: Children with non-infectious uveitis from January 2011 to December 2015 were identified. Data was collected at baseline, 1, 3, 5, and 10 years post diagnosis. The incidence rates of visual impairment, structural ocular complications and surgical intervention were calculated. Using logistic regression the association between various baseline characteristics and later visual impairment was investigated.

Results: Of the 166 children, 60.2\% $(n=100)$ had a systemic disease association. 72.9\% $(n=121)$ children received methotrexate, 58 children progressed to a biologic. The incidence rates of visual acuity loss to $>0.3$ LogMAR (6/12) and to $\geq 1.0$ LogMAR (6/60) were 0.05/Eye Year (EY) and 0.01/EY, respectively. Visual outcomes in the Juvenile Idiopathic Arthritis associated Uveitis (JIA-U) and Idiopathic Uveitis cohorts were not statistically significant. Of the 293 affected eyes, posterior synechiae was the predominant complication on presentation, while cataract had the highest incidence rate $(0.05 / E Y)$. On direct comparison, children with JIA-U were statistically significantly more likely to develop glaucoma while children with Idiopathic Uveitis were statistically significantly more likely to develop macular oedema.

Conclusion: One third of children received a biological therapy, reflecting increasing utilisation and importance of biological agents in the management of inflammatory conditions. Rates of visual impairment and ocular complications are an improvement on previously published data.
\end{abstract}

Keywords: Uveitis, Biologics, Paediatrics, Visual outcomes

\section{Background}

Uveitis is rare in the paediatric population, with an estimated incidence of 4.3 per 100,000 and a prevalence of 27.9 per $100,000[1,2]$ but there is a high rate of chronic disease [3]. Non-infectious uveitis accounts for between 69 and $95 \%$ of childhood uveitis [4-7]. Juvenile Idiopathic Arthritis associated Uveitis (JIA-U) makes up 41$47 \%$ of cases but equally in $28-51 \%$ of children no cause is found [7-9]. Ocular complications including cataract,

\footnotetext{
* Correspondence: avramanan@hotmail.com

${ }^{\dagger}$ Athimalaipet V. Ramanan and Catherine M. Guly contributed equally to this work.

${ }^{1}$ University Hospitals Bristol NHS Foundation Trust, Bristol, UK

${ }^{2}$ Translational Health Sciences, Bristol Medical School, Faculty of Health

sciences, Bristol, UK

Full list of author information is available at the end of the article
}

glaucoma and macular oedema are reported in up to $76 \%$ of all cases of paediatric uveitis [4]. Visual impairment is common but reporting is variable making comparisons difficult. Using incidence rates of visual impairment, visual loss in children with JIA-U has been reported at 0.10/EY [10]. Other studies have reported overall rates of visual impairment in at least one affected eye between 17 and $37 \%$ and 5 year rates of 36.36 and $15.1 \%$ for visual acuity worse then $20 / 50$ and $20 / 200$ respectively $[3,4,8]$.

Topical corticosteroids carry a risk of cataract and glaucoma [11] and increasingly early use of immunosuppressive agents is advocated in chronic non-infectious uveitis to reduce the risk of visual loss $[12,13]$. Methotrexate is the most commonly prescribed immunosuppressive therapy in

(C) The Author(s). 2018 Open Access This article is distributed under the terms of the Creative Commons Attribution 4.0 International License (http://creativecommons.org/licenses/by/4.0/), which permits unrestricted use, distribution, and reproduction in any medium, provided you give appropriate credit to the original author(s) and the source, provide a link to the Creative Commons license, and indicate if changes were made. The Creative Commons Public Domain Dedication waiver (http://creativecommons.org/publicdomain/zero/1.0/) applies to the data made available in this article, unless otherwise stated. 
paediatric uveitis [13], but $27-48 \%$ children do not achieve control of inflammation and $20 \%$ experience adverse events [14-16]. Use of infliximab in the management of refractory paediatric uveitis was first reported in 2005 [17]. The following year a small case series of adalimumab for paediatric uveitis was published [18]. Adalimumab was licenced for adult and paediatric non-infectious uveitis in 2016 and 2017 respectively following successful outcome of randomised controlled trials (RCTs) [19, 20].

There is a paucity of data on longer term outcomes of paediatric uveitis (including JIA-U) in the era of biologic treatment. The aim of this retrospective study is to determine the visual outcomes and ocular complications of children attending a tertiary service covering the South-West of England and the South of Wales (approximate population of 5.5 million).

\section{Methods}

\section{Patient identification}

Bristol Eye Hospital Databases were reviewed to identify all patients with uveitis. Children were included if they had been diagnosed with non-infectious uveitis prior to the age of 16 years and been managed at the Bristol Eye Hospital between January 2011and December 2015. Children referred to the service were either resident in Bristol and referred from local medical services (primary referrals) or lived outside Bristol and were referred from surrounding ophthalmology services(tertiary referrals).

\section{Data collection}

Data was collected retrospectively at standard time intervals; diagnosis, and 1, 3, 5 and 10 years. The appointment closest to the time interval was selected for analysis. Demographic data included age at diagnosis, gender and ethnicity. Clinical uveitis details included aetiology, laterality, anatomical location using Standardization of Uveitis Nomenclature (SUN) criteria [21] and structural complications. Elevated intraocular pressure (IOP) was defined as $>21 \mathrm{mmHg}$ and hypotony as $<5 \mathrm{mmHg}$. Pharmacological and surgical treatments were documented. Visual acuity was recorded in $\log M A R$. LogMAR is the logarithmic representation of visual acuity. It is the accepted standard of representing visual acuity in research as it is recognised to be more reliable, discriminative and repeatable when compared to the classic Snellen's chart [22]. Visual impairment was stratified by severity as $\log$ MAR > 0.3 (worse than 6/12) or $\geq 1.0$ (6/60 or worse) [21].

\section{Statistical analysis}

The incidence rates of visual impairment and structural ocular complications were calculated for the whole population, and for the JIA-U and idiopathic uveitis cohorts. Not all patients contributed at all time points. Incidence rates were calculated per at risk eye year using longitudinal data analysis to account for variable length of follow up [23]. Year of complication onset was not recorded for 20 out of a total of 247 events (band keratopathy $n=5$, cataracts $n=8$, glaucoma $n=3$, posterior synechiae $n=1$, elevated IOP $n=3$ ). A year of onset of 4 years was used for these events as this was the nearest whole year to the study cohort's mean years of follow-up (range from 3.8 to 4.5 years). The association between various baseline characteristics and later visual impairment was investigated using logistic regression (crude and adjusting for age and sex). Analyses allowed for intragroup correlation between eyes in patients with bilateral events. Analyses were performed using Stata 14 statistical software (Stata Corp, College Station, Texas).

Data collection was approved by the hospital trust and ethics committee approval was not required.

\section{Results}

Patient demographics and clinical characteristics of the 166 patients included in the study are outlined in Table 1. Of the 50 children with unilateral uveitis on presentation, 11 progressed to bilateral disease. A total of 293 affected eyes were included in the study. Baseline information was available for 234 eyes in total. $60.2 \%$ of patients had an underlying systemic disease association (Fig. 1). JIA was the primary associated systemic disease, however Tubulointerstitial Nephritis and Uveitis (TINU; 4 patients, 6 eyes), Blau (3 patients; 6 eyes), Behcet ( 1 patient; 1 eye) and undifferentiated inflammatory disease (1 patient; 2 eyes) was also present. Anterior uveitis was the most common form of uveitis occurring in 125 patients (75.3\%). In JIA 89 out of 91 patients (97.8\%) had anterior uveitis. Unfortunately time to diagnosis data was not available for the cohort. Of the 93 tertiary referral patients (i.e. referred from surrounding ophthalmology services for subspecialist opinion); 64.5, 8.6, 10.8, 6.5 and 9.7\% were seen at the tertiary centre within 3 months, 1 year, 3 years, 5 years and 10 years of diagnosis respectively.

Medications are recorded in Table 1. The first line systemic immunosuppressive agent for all children was methotrexate. Of the 166 patients, 39 (23.5\%) children received additional conventional DMARD therapy; either as monotherapy or in combination with Methotrexate (20/91 JIA patients, 17/66 idiopathic uveitis patients and 2/9 patients with other systemic diseases). 58 children $(34.4 \%)$ received a biologic agent and 14 children $(8.4 \%)$ required $\geq 2$ biologics over the follow up period. No child received a biologic agent at baseline. Biologics were more likely to be delivered to children with JIA-U (43 children; 47.3\%) than those with idiopathic uveitis (10 children; $15.2 \%) .7$ (10.6\%) children with idiopathic uveitis did not require treatment $(p=<0.001)$.

A total of 678 person years and 1216 eye years (EY) of follow up were available. For the total population the 
Table 1 Patient Demographic and Clinical Characteristics

\begin{tabular}{|c|c|c|c|c|}
\hline & Cohort (\%) & JIA (\%) & Other Associated Systemic Disease(\%) & Idiopathic (\%) \\
\hline No. of Patients & 166 & $91(54.8)$ & $9(5.4)$ & $66(39.8)$ \\
\hline Female & 99 (59.6) & $62(68.1)$ & $2(22.2)$ & $35(53)$ \\
\hline \multicolumn{5}{|l|}{ Age at diagnosis } \\
\hline Average & $8.03 y$ & $5.9 y$ & $10.5 y$ & $10.7 y$ \\
\hline Median & $7 y$ & $5 y$ & $12 y$ & $11 y$ \\
\hline \multicolumn{5}{|l|}{ Referral type } \\
\hline Tertiary & $93(56)$ & $56(61.5)$ & $6(66.7)$ & $31(47)$ \\
\hline \multicolumn{5}{|l|}{ Ethnicity } \\
\hline Caucasian & $128(77.1)$ & 73(80.2) & $6(66.7)$ & $49(74.2)$ \\
\hline Asian & $8(4.8)$ & $2(2.2)$ & $2(22.2)$ & $4(6)$ \\
\hline African & $1(0.6)$ & 0 & 0 & $1(1.5)$ \\
\hline Other & $7(4.2)$ & $2(2.2)$ & $1(11.1)$ & $4(6)$ \\
\hline Unknown & $22(13.3)$ & $14(15.4)$ & 0 & $8(12.1)$ \\
\hline \multicolumn{5}{|c|}{ Laterality on presentation } \\
\hline Bilateral & $116(69.9)$ & $62(68.1)$ & $5(55.6)$ & $49(74.2)$ \\
\hline \multicolumn{5}{|l|}{ Anatomic Localisation } \\
\hline Anterior & $125(75.3)$ & $89(97.8)$ & $5(55.6)$ & $31(47)$ \\
\hline Intermediate & $29(17.5)$ & 0 & $1(11.1)$ & $28(42.4)$ \\
\hline Posterior & $1(0.6)$ & 0 & 0 & $1(1.5)$ \\
\hline Panuveitis & $11(6.6)$ & $2(2.2)$ & $3(33.3)$ & $6(9.1)$ \\
\hline \multicolumn{5}{|c|}{ Visual Impairment at baseline (per eye) } \\
\hline$>0.3 \log M A R$ & $43(18.4)$ & $22(18.6)$ & $3(27.3)$ & $18(17.1)$ \\
\hline$\geq 1.0 \log M A R$ & $10(4.3)$ & $7(5.9)$ & 0 & $3(2.9)$ \\
\hline \multicolumn{5}{|c|}{ Medication use over study } \\
\hline \multicolumn{5}{|l|}{ Corticosteroids } \\
\hline Topical CS & $155(93.4)$ & $91(100)$ & $8(88.9)$ & $56(84.8)$ \\
\hline Systemic CS & $58(34.9)$ & $28(30.8)$ & $7(77.8)$ & $23(34.8)$ \\
\hline Peri/Intraocular & $12(7.2)$ & $6(6.6)$ & $3(33.3)$ & $6(9.1)$ \\
\hline \multicolumn{5}{|l|}{ Steroids } \\
\hline Conventional DMARD & $121(72.9)$ & $82(90.1)$ & $6(66.7)$ & $33(50)$ \\
\hline Methotrexate & $121(72.9)$ & $82(90.1)$ & $6(66.7)$ & $33(50)$ \\
\hline Only Methotrexate & 47 (28.3\%) & $35(38.5)$ & $1(11.1)$ & $11(16.7)$ \\
\hline Mycophenolate & $36(21.7)$ & $19(20.9)$ & $2(22.2)$ & $15(22.7)$ \\
\hline \multicolumn{5}{|l|}{ mofetil } \\
\hline Tacrolimus & $6(3.6)$ & $3(3.3)$ & 0 & $3(4.5)$ \\
\hline Ciclosporin & $3(1.8)$ & $2(2.2)$ & 0 & $1(1.5)$ \\
\hline Biologics & $58(34.9)$ & $43(47.3)$ & $5(55.6)$ & $10(15.2)$ \\
\hline Adalimumab & $52(31.3)$ & $38(41.8)$ & $5(55.6)$ & $9(13.6)$ \\
\hline Infliximab & 19 (11.4) & $14(15.4)$ & $4(44.4)$ & $1(1.5)$ \\
\hline Abatacept & $3(1.8)$ & $3(1.8)$ & 0 & 0 \\
\hline Tocilizumab & $2(1.2)$ & $2(1.2)$ & 0 & 0 \\
\hline
\end{tabular}

At presentation 118 eyes JIA, 11 other associated systemic diseases and 105 idiopathic 


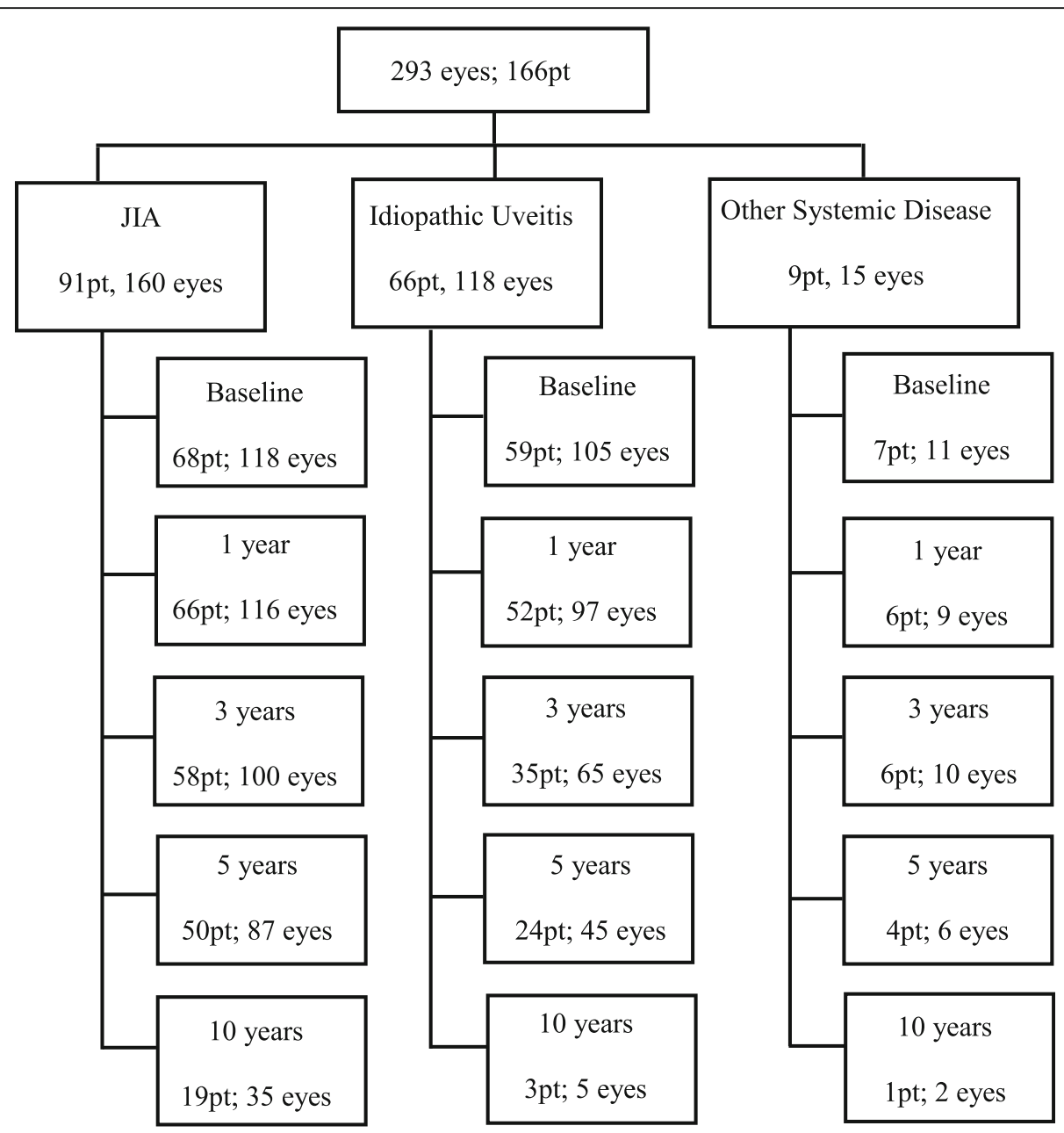

Fig. 1 Data Available at Standard Time Intervals Detailed information of the number of patients and affected eyes per aetiology at baseline, 1 year, 3 years, 5 years and 10 years post diagnosis

median duration of follow up was 5 years. Children with JIA-U had a longer duration of follow up when compared to children with idiopathic uveitis (median 5 years vs 3 years). Availability of follow up data is outlined in Fig. 1. 34 children contributed only 1 visit; the majority of these children (21 children) were tertiary referrals seen at least 1 year post diagnosis. The median number of evaluation visits per patient was 3. Rates of complications at presentation and incidence rates of newly diagnosed complications are summarised in Table 2 . The rates of visual acuity loss over the period of observation to $>0.3 \operatorname{LogMAR}$ and to $\geq 1.0$ LogMAR among affected eyes were $0.05 / \mathrm{EY}$ and $0.01 / \mathrm{EY}$, respectively. At presentation 81/234 eyes (34.6\%) had at least one ocular uveitis associated complication, of which posterior synechiae was the most common (43 eyes; 18.4\%). The rate of newly diagnosed band keratopathy and posterior synchiae was $0.02 / \mathrm{EY}$. Children with JIA-U were more likely to develop raised IOP $(p=0.05)$ and glaucoma $(p=$ 0.002) when compared to children with idiopathic uveitis, while children with idiopathic uveitis were more likely to developed macular oedema $(p=0.01)$ over the period of follow up. Cataract was the frequent complication to occur over the follow up period with an incidence rate of 0.05/ EY.Three eyes ( 3 children) had amblyopia. All three eyes had visual impairment, 2 eyes had $\geq 1.0 \operatorname{logMAR}$ and one had $>0.3 \log M A R$. There was no statistical difference between the rate of visual impairment between children with anterior uveitis versus children with intermediate uveitis. The incidence rate of visual impairment $>0.3 \log$ MAR for anterior uveitis was 0.04/EY (CI95\% 0.03-0.06) compared to $0.05 / \mathrm{EY}$ (CI95\% 0.02-0.11) for children with intermediate uveitis $(p=0.80)$. No child with intermediate uveitis developed a visual impairment of $\geq 1.0 \log M A R$ over the study period whereas the incidence in children with anterior uveitis was $0.01 /$ EY (CI95\% 0.01-0.02) $(p=0.13)$. Additionally, there was no significant difference between rates of visual impairment in those children with JIA-U anterior uveitis and non-JIA-U anterior uveitis. Children with JIA-U 


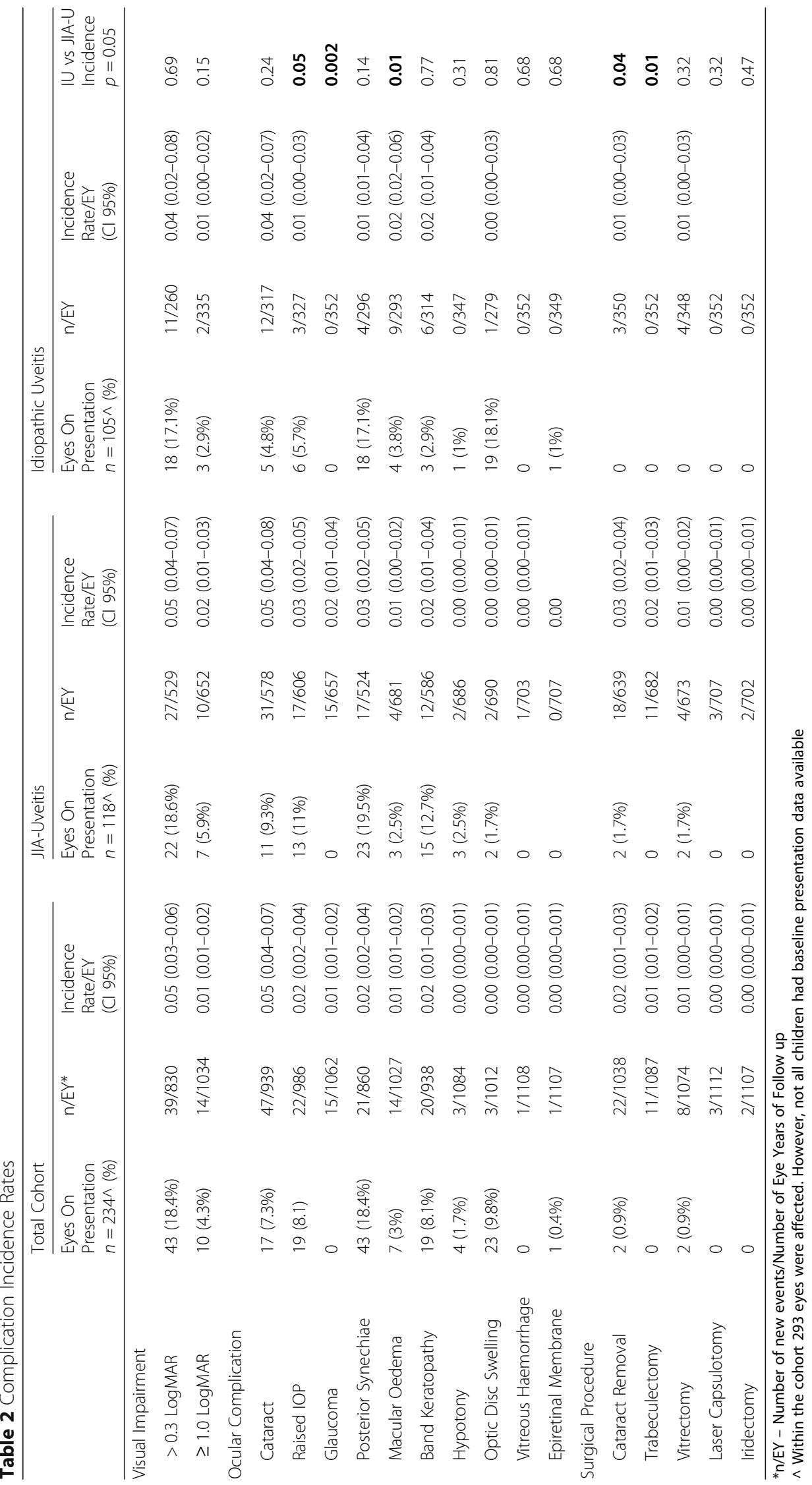


anterior uveitis had an incidence rate of visual impairment $>0.3 \log$ MAR of $0.05 / \mathrm{EY}$ (CI95\% 0.03-0.07) compared to $0.02 / \mathrm{EY}(\mathrm{CI} 95 \% \quad 0.01-0.07)$ in the non-JIA-U anterior group $(p=0.19)$. The rate of visual impairment $\geq 1.0 \log$ MAR between the JIA-U anterior uveitis and the non-JIA-U anterior uveitis cohort was 0.01/EY (CI95\% 0.00-0.05) and 0.01/EY (CI95\% 0.01-0.03) respectively $(p=0.5)$.

Surgical procedures were required in 38 eyes and in some cases one eye received multiple procedures. Cataract extraction was the most common procedure, performed in 24 eyes $(0.9 \%$ within 3 months of presentation; Incidence rate $0.02 / \mathrm{EY}) .20$ eyes received an intraocular lens implant and 3 remained aphakic. Lens insertion data was not available for 1 eye. Trabeculectomy was required in 11 eyes $(0.01 / \mathrm{EY})$ and vitrectomy in 10 eyes $(0.9 \%$ within 3 months of presentation; $0.01 / \mathrm{EY})$. Indication for vitrectomy is as follows; uncontrolled inflammation despite aggressive therapy (3 eyes), vitreal debris (3 eyes), cyclitic membrane ( 1 eye) and undocumented reasons ( 3 eyes) Patients with JIA were more likely to require cataract removal and trabeculectomy than those with idiopathic uveitis ( $p=0.04$ and $p=0.01$ respectively) over the period of follow up. Two children required an enucleation at 5 and 10 years follow up. Both eyes had severe sight loss and required removal due to chronic pain.

Using logistic regression, demographic and clinical characteristics on presentation were analysed to determine whether they were predictive of visual impairment. These characteristics are detailed in Table 3. Tertiary referral patients were statistically more likely to develop a visual impairment of $\operatorname{logMAR}>0.3(p=0.03)$ and $\geq 1.0$ $(p=0.05)$. The presence of posterior synechiae at presentation was also a risk factor for visual impairment $\geq 1.0$ $\log$ MAR $(p=0.01)$.

\section{Discussion}

We report a large cohort of children with non-infectious uveitis managed in a UK tertiary unit. Use of systemic immunosuppression was high with $72.9 \%$ of children receiving methotrexate and 34.9\% receiving a biologic agent. The recent publication of the SYCAMORE trial [20] has supported the efficacy of rapid escalation to biologics in the management of children with JIA-U refractory to conventional immunosuppressive therapy.

Despite published evidence that up to $73 \%$ of children experience improvement in intraocular inflammation with methotrexate [14], in this population methotrexate refractory disease was common. Of the 121 children

Table 3 Patient Risk Factors at Baseline for Visual Impairment

\begin{tabular}{|c|c|c|c|c|}
\hline & \multicolumn{2}{|c|}{ Risk of Visual Impairment $>0.3 \log M A R$} & \multicolumn{2}{|c|}{ Risk of Visual Impairment $\geq 1.0 \log M A R$} \\
\hline & OR $(95 \% \mathrm{Cl})$ & $p(0.05)$ & & $p(0.05)$ \\
\hline \multicolumn{5}{|l|}{ Demographics } \\
\hline Age at uveitis diagnosis & $0.97(0.87-1.08)$ & 0.56 & $1.02(0.88-1.19)$ & 0.76 \\
\hline Bilateral Disease & $1.23(0.46-3.34)$ & 0.68 & $0.45(0.12-1.65)$ & 0.23 \\
\hline Female & $1.43(0.61-3.36)$ & 0.41 & $1.24(0.38-4.12)$ & 0.72 \\
\hline Tertiary Referral & $2.71(1.12-6.56)$ & 0.03 & $4.59(0.98-21.47)$ & 0.05 \\
\hline \multicolumn{5}{|l|}{ Aetiology } \\
\hline$J \mid A$ & $2.05(0.88-4.77)$ & 0.10 & $2.15(0.62-7.43)$ & 0.23 \\
\hline Idiopathic & $0.54(0.23-1.29)$ & 0.16 & $0.23(0.05-1.09)$ & 0.07 \\
\hline \multicolumn{5}{|l|}{ Uveitis Characteristics } \\
\hline Anterior Uveitis & $0.89(0.37-2.14)$ & 0.80 & $0.89(0.26-3.07)$ & 0.85 \\
\hline Bilateral Disease & $1.23(0.46-3.34)$ & 0.68 & $0.45(0.12-1.65)$ & 0.23 \\
\hline \multicolumn{5}{|l|}{ Complications at Baseline } \\
\hline Band keratopathy & $1.24(0.24-6.37)$ & 0.80 & $1.12(0.15-8.53)$ & 0.92 \\
\hline Cataracts & $1.43(0.29-6.99)$ & 0.66 & $5.16(0.91-29.23)$ & 0.06 \\
\hline Posterior synechiae & $0.84(0.26-2.71)$ & 0.77 & $4.91(1.38-17.39)$ & 0.01 \\
\hline Elevated IOP & $0.35(0.05-2.51)$ & 0.29 & 1.00 & \\
\hline Macular oedema & $1.09(0.12-10.07)$ & 0.94 & 1.00 & \\
\hline Hypotony & $2.20(0.19-25.31)$ & 0.53 & $7.08(0.64-78.00)$ & 0.11 \\
\hline Optic disc swelling & $0.98(0.29-3.30)$ & 0.97 & $2.05(0.47-8.88)$ & 0.34 \\
\hline
\end{tabular}


started on methotrexate, 58 (47.9\%) required third line therapy in the form of one or more biologic agent. Tertiary referral patients were 1.6 times more likely to be treated with a biologic when compared to primary referral patients (41.9\% vs $26 \%)$. This difference was statistically significant $(p=0.03)$. Children with an associated systemic disease were statistically more likely to receive a biologic than those with idiopathic uveitis ( $48 \%$ vs $15.2 \% p=<0.001$ ). However the rates of visual impairment were similar in the JIA-U and idiopathic uveitis cohorts and so the difference in treatment may represent a milder disease course of idiopathic uveitis or the longer median duration of follow up of the JIA-U cohort. Overall rates of biologic use are higher than previous reports. The rate of biologic use in the idiopathic uveitis cohort (15.2\%) is slightly lower than reported in Sardar et al. [24] where $21 \%$ of patients required third line therapy. However, the proportion of children with idiopathic panuveitis and posterior uveitis was slightly higher in the French cohort, which may explain the slightly higher rate of biologic use. In 2007 Saurenmann et al. [25] reported that $11 \%$ of children with JIA-U received an anti-TNF agent but over the last 10 years biologics have become more widely available and accepted practice for refractory JIA-U.

Visual outcomes in this cohort are an improvement on previously published data. Thorne et al. [10] reported in a population of children with JIA-U rates of visual impairment of $6 / 15$ or worse $(\geq 0.4 \operatorname{logMAR})$ and $6 / 60$ or worse $(\geq 1.0 \log$ MAR) of $0.10 /$ UEY and $0.08 / E Y$ respectively. In our study, the incidence rate of visual impairment in those children with JIA-U was $0.05 / \mathrm{EY}(>0.3 \log \mathrm{MAR})$ and $0.02 / \mathrm{EY} \quad(\geq 1.0 \log$ MAR). While JIA-U had a higher incidence rate of visual impairment compared to idiopathic uveitis, the difference was not significant. Comparison between rates of ocular complications within our study population and previous published data is outlined in Table 4. In this study eight children developed bilateral visual impairment $>0.3 \log$ MAR and only one child had bilateral visual impairment $\geq 1.0 \log M A R$ at final documented contact.

Uncertainties remain on the optimum time to initiate systemic therapy and the duration of systemic treatments for children with uveitis as well as the visual outcomes of those children with uveitis moving on to adulthood. Evidence for biologic treatments other than Adalimumab remains limited in childhood uveitis. A trial of subcutaneous tocilizumab for JIA-U is currently underway which hopefully will provide further evidence for the use of IL- 6 blockade (APTITUDE) [26]. Biologic agents are expensive and carry an increased risk of infection and other side effects [27-30] which needs to be balanced against the potential benefits in reducing sight loss. We also recognise the burden to children and their families managing frequent hospital appointments, eye drops and immunosuppression regimes. Even in the absence of long term complications, uveitis can have emotional and psychological consequences for the child and family encompassing anxiety, anger and fear of the future [31].

As a retrospective study we acknowledge certain limitations to the study. The duration of follow up within the patient cohort was unequal in some cases, and as a result data is not available for all patients at all time points. Additionally, in a tertiary centre there may be overrepresentation of severe cases, and children who had mild disease may have not had been included as they are no longer managed by the service. Unfortunately therapy adverse events were not captured in this study. The era of biologic therapy has brought improvements in visual outcomes for children with uveitis but

Table 4 JIA-U Ocular Outcomes per affected eyes

\begin{tabular}{|c|c|c|c|c|c|c|c|c|}
\hline \multicolumn{5}{|l|}{$J I A-U$} & \multicolumn{4}{|c|}{ Idiopathic Uveitis/Pars Plantis } \\
\hline & $\begin{array}{l}\text { Current Study } \\
(n=91)\end{array}$ & $\begin{array}{l}\text { Tugal-Tutkun [9] } \\
1996(n=100)\end{array}$ & $\begin{array}{l}\text { Kadayifçilar } \\
{[33] 2003} \\
(n=55)\end{array}$ & $\begin{array}{l}\text { Kump7 } \\
2005 \\
(n=165)\end{array}$ & $\begin{array}{l}\text { Current Study } \\
(n=118)\end{array}$ & $\begin{array}{l}\text { Tugal-Tutkun }{ }^{9} \\
1996(n=88)\end{array}$ & $\begin{array}{l}\text { Kadayifçilar } \\
{[33] 2003} \\
(n=134)\end{array}$ & $\begin{array}{l}\text { Kump }^{7} \\
2005 \\
(n=202)\end{array}$ \\
\hline Cataract & $42(26.3 \%)$ & $71(71 \%)$ & $16(32.7 \%)$ & $105(64 \%)$ & $17(14.4 \%)$ & $33(37.5 \%)$ & $41(30.6 \%)$ & $60(29.6 \%)$ \\
\hline Glaucoma & $15(9.4 \%)$ & $30(30 \%)$ & $1(2 \%)$ & $33(20 \%)$ & 0 & $2(2.3 \%)$ & $7(5.2 \%)$ & $29(14.4 \%)$ \\
\hline Band Keratopathy & $27(16.9 \%)$ & $66(66 \%)$ & $5(10 \%)$ & $76(46 \%)$ & $9(7.6 \%)$ & $16(18.2 \%)$ & $13(9.7 \%)$ & $24(11.9 \%)$ \\
\hline Post. Synechiae & $40(25 \%)$ & - & - & $96(58 \%)$ & $22(18.6 \%)$ & - & - & $49(24.3 \%)$ \\
\hline Optic Disc Swelling & $4(2.5 \%)$ & $6(6 \%)$ & $1(2 \%)$ & $5(3 \%)$ & $20(16.9 \%)$ & $10(11.4 \%)$ & $6(4.5 \%)$ & $14(6.9 \%)$ \\
\hline Hypotony & $5(3.1 \%)$ & 19 (19\%) & $3(5.5 \%)$ & $17(10 \%)$ & $1(0.8 \%)$ & $2(2.3 \%)$ & $1(0.7 \%)$ & $1(0.5 \%)$ \\
\hline Macular Oedema & $7(4.4 \%)$ & - & - & - & $13(11 \%)$ & - & - & - \\
\hline Vitreous Haemorrhage & $1(0.6 \%)$ & $3(3 \%)$ & 0 & 0 & 0 & $8(5 \%)$ & $2(1.5 \%)$ & $3(1.5 \%)$ \\
\hline Epiretina Membranel & 0 & - & $1(2 \%)$ & $17(10 \%)$ & $1(0.8 \%)$ & - & - & $20(9.9 \%)$ \\
\hline
\end{tabular}


there is still potential for ongoing improvement in outcomes in the future.

Improved visual outcomes may be a result of a combination of factors. New therapies are capable of controlling inflammation refractory to conventional immunosuppressive therapy [20]. However clinical practice has evolved over the past decade to include robust and audited JIA uveitis screening standards [32], early treatment and close monitoring of affected children within a multidisciplinary team. The establishment of a combined paediatric rheumatology and uveitis clinic with specialist nurses at the Bristol Eye Hospital has been crucial in providing timely and effective monitoring and management for children with complex uveitis. The implementation of these practices may have contributed to improved outcomes.

\section{Conclusion}

This study has demonstrated an encouraging improvement in the rate of ocular complications and visual impairment in children with non-infectious uveitis when compared to previous publications. Notably, the rate of biologic use was high (34.9\%), reflecting their increasing importance in modern immunomodulation. Visual outcomes between the JIA-U and idiopathic uveitis cohorts were not significant. Cataract development was the most common ocular complication within the cohort.

\section{Abbreviations}

Cl: Confidence Interval; DMARD: Disease Modifying Antirheumatic Drug; EY: Eye Year; IOP: Intraocular Pressure; JIA: Juvenile Idiopathic Arthritis; JIAU: Juvenile Idiopathic Arthritis associated Uveitis; $\mathrm{mmHg}$ : Millimeter of mercury; Pt: Patient; RCT: Randomised Control Trial; SUN: Standardization of Uveitis Nomenclature; TINU: Tubulointerstitial Nephritis and Uveitis

\section{Availability of data and materials}

The datasets used and/or analysed during the current study are available from the corresponding author on reasonable request.

\section{Authors' contributions}

MC engaged in data collection, data analysis and interpretation and drafting of the submitted article, AVR was involved in the conception and design of the study, data interpretation and engaged in critical revision of the article, AC provided statistical analysis of the data and engaged in critical revision of the article,.AD was involved in the conception and design of the study, data interpretation and engaged in critical revision of the article, SC was involved in the conception and design of the study, data interpretation and engaged in critical revision of the article, FR engaged in data collection and study design,CG was involved in the conception and design of the study, data interpretation and engaged in critical revision of the article, All authors read and approved the final manuscript.

\section{Ethics approval and consent to participate}

Not applicable.

\section{Consent for publication}

Not Applicable.

\section{Competing interests}

$M C$ has received financial support from Abbvie to attend one conference, AD has received consultancy for Abbvie, Sanofi, Gyroscope, Roche. AVR has received honoria from Abbvie and is Co-Chief Investigator of Sycamore Study which was funded by NIHR and Arthritis Research UK. CG has received fees from Abbvie SC, FR, and AC have no conflicts to declare.

\section{Publisher's Note}

Springer Nature remains neutral with regard to jurisdictional claims in published maps and institutional affiliations.

\section{Author details}

${ }^{1}$ University Hospitals Bristol NHS Foundation Trust, Bristol, UK. ${ }^{2}$ Translational Health Sciences, Bristol Medical School, Faculty of Health sciences, Bristol, UK. ${ }^{3}$ BHF Centre for Cardiovascular Science, Queen's Medical Research Institute, University of Edinburgh, Edinburgh, UK. ${ }^{4} \mathrm{MRC}$ Integrative Epidemiology Unit, Population Health Sciences, University of Bristol, Bristol, UK. ${ }^{5}$ National Institute for Health Research (NIHR) Biomedical Research Centre at Moorfield Eye Hospital, London, UK. ${ }^{6}$ University College London Institute of Ophthalmology, London, UK.

Received: 11 April 2018 Accepted: 19 July 2018

Published online: 06 August 2018

References

1. Päivönsalo-Hietanen T, Tuominen J, Saari KM. Uveitis in children: population-based study in Finland. Acta Ophthalmol Scand. 2000 Feb; 78(1):84-8.

2. Zierhut M, Michels $H$, Stubiger $N$, Besch D, Deuter $C$, Heiligenhaus A. Uveitis in Children. Int Ophthalmol Clin. 2005 Spring;45(2):135-56.

3. Smith JA, Mackensen F, Sen HN, Leigh JF, Watkins AS, Pyatetsky D, Tessler HH, Nussenblatt RB, Rosenbaum JT, Reed GF, Vitale S, Smith JR, Goldstein DA. Epidemiology and course of disease in childhood uveitis. Ophthalmology. 2009 Aug;116(8):1544-51.

4. de Boer J, Wulffraat N, Rothova A. Visual loss in uveitis of childhood. Br J. Ophthalmol. 2003;87:879-84

5. Hettinga YM, de Groot-Mijnes JD, Rothova A, de Boer JH. Infectious involvement in a tertiary center pediatric uveitis cohort. Br J Ophthalmol. 2015;99(1):103-7.

6. Paroli MP, Spinucci G, Liverani M, Monte R, Pezzi PP. Uveitis in childhood: an Italian clinical and epidemiological study. Ocul Immunol Inflamm. 2009; 17(4):238-42.

7. Kump LI, Cervantes-Castaneda RA, Androudi SN, Foster CS. Analysis of pediatric uveitis cases at a tertiary referral center. Ophthalmology. 2005; 112(7):1287-92

8. Edelsten C, Reddy MA, Stanford MR, Graham EM. Visual loss associated with pediatric uveitis in English primary and referral centers. Am J Ophthalmol. 2003;135(5):676-80.

9. Tugal-Tutkun I, Havrlikova K, Power WJ, Foster CS. Changing patterns in uveitis of childhood. Ophthalmology. 1996;103(3):375-83.

10. Thorne JE, Woreta F, Kedhar SR, Dunn JP, Jabs DA. Juvenile idiopathic arthritis-associated uveitis: incidence of ocular complications and visual acuity loss. Am J Ophthalmol. 2007;143(5):840-6.

11. Thorne JE, Woreta FA, Dunn JP, Jabs DA. Risk of cataract development among children with juvenile idiopathic arthritis-related uveitis treated with topical corticosteroids. Ophthalmology. 2010 Jul;117(7):1436-41.

12. Sen ES, Dick AD, Ramanan AV. Uveitis associated with juvenile idiopathic arthritis. Nat Rev Rheumatol. 2015 Jun;11(6):338-48.

13. Heiligenhaus A, Michels H, Schumacher C, Kopp I, Neudorf U, Niehues T, et al. Evidence-based, interdisciplinary guidelines for anti-inflammatory treatment of uveitis associated with juvenile idiopathic arthritis. Rheumatol Int. 2012;32(5):1121-33.

14. Simonini G, Paudyal P, Jones G, Cimaz R, Macfarlane G. Current evidence of methotrexate efficacy in childhood chronic uveitis: a systematic review and meta-analysis approach. Rheumatology. 2013;2013(52):825-31.

15. Gangaputra S, Newcomb CW, Liesegang TL, Kacmaz RO, Jabs DA, LevyClarke GA, Nussenblatt RB, Rosenbaum JT, Suhler EB, Thorne JE, Foster $\mathrm{CS}$, Kempen $\mathrm{JH}$. Methotrexate for ocular inflammatory diseases. Ophthalmology. 2009;116:2188-98.

16. Samson CM, Waheed N, Baltatzis S, Foster CS. Methotrexate therapy for chronic noninfectious uveitis: analysis of a case series of 160 patients. Ophthalmology. 2001;108(6):1134-9.

17. Richards JC, Tay-Kearney ML, Murray K, Manners P. Infliximab for juvenile idiopathic arthritis-associated uveitis. Clin Exp Ophthalmol. 2005;33(5):461-8. 
18. Vazquez-Cobian LB, Flynn T, Lehman TJ. Adalimumab therapy for childhood uveitis. J Pediatr. 2006 Oct; 149(4):572-5.

19. Jaffe $G J$, Dick $A D$, Brézin $A P$, Nguyen $Q D$, Thorne JE, Kestelyn $P$, BarisaniAsenbauer T, Franco P, Heiligenhaus A, Scales D, Chu DS, Camez A, Kwatra NV, Song AP, Kron M, Tari S, Suhler EB. Adalimumab in patients with active noninfectious uveitis. N Engl J Med. 2016 Sep 8;375(10):932-43.

20. Ramanan AV, Dick AD, Jones AP, McKay A, Williamson PR, CompeyrotLacassagne S, Hardwick B, Hickey H, Hughes D, Woo P, Benton D, Edelsten C, Beresford MW, SYCAMORE Study Group. N Engl I Med. 2017;376(17):1637-46.

21. Jabs DA, Nussenblatt RB, Rosenbaum JT; Standardization of uveitis nomenclature (SUN) working group. Standardization of uveitis nomenclature for reporting clinical data. Results of the first international workshop. Am J Ophthalmol 2005;140(3):509-516.

22. Elliott DB. The good (logMAR), the bad (Snellen) and the ugly (BCVA, number of letters read) of visual acuity measurement. Ophthalmic Physiol Opt. July;36(4):355-8.

23. Jabs DA. Improving the reporting of clinical case series. Am J Ophthalmol. 2005;139(5):900-5.

24. Sardar E, Dusser P, Rousseau A, Bodaghi B, Labetoulle M, Koné-Paut I. Retrospective study evaluating treatment decisions and outcomes of childhood uveitis not associated with juvenile idiopathic arthritis. J Pediatr. 2017;186:131-7.

25. Saurenmann RK, Levin AV, Feldman BM, Rose JB, Laxer RM, Schneider R, Silverman ED. Prevalence, risk factors, and outcome of uveitis in juvenile idiopathic arthritis: a long-term followup study. Arthritis Rheum. 2007;56(2):647-57.

26. A phase II trial of tocilizumab in anti-TNF refractory patients with JIA associated uveitis (APTITUDE study) [Internet]. BioMed Central. 2015 [cited 22 Dec 2015]. Available from: http://www.isrctn.com/ISRCTN95363507.

27. Davies R, Southwood TR, Kearsley-Fleet L, Lunt M, Hyrich KL. British Society for Paediatric and Adolescent Rheumatology Etanercept Cohort Study. Medically significant infections are increased in patients with juvenile idiopathic arthritis treated with etanercept: results from the British Society for Paediatric and Adolescent Rheumatology Etanercept Cohort Study. Arthritis Rheum. 2015;67(9):2487-94.

28. Beukelman T, Xie F, Chen L, Baddley JW, Delzell E, Grijalva CG, et al. Rates of hospitalized bacterial infection associated with juvenile idiopathic arthritis and its treatment. Arthritis Rheum. 2012;64(8):2773-80.

29. Beukelman T, Xie F, Baddley J, Chen L, Mannion ML, Saag KG, Zhang J, Curtis JR. The Risk of Hospitalized Infection Following Initiation of Biologic Agents Versus Methotrexate in the Treatment of Juvenile Idiopathic Arthritis. Arthritis Res Ther. 2016;18:210.

30. Lee HH, Song IH, Friedrich M, Gauliard A, Detert J, Röwert J, Audring H, Kary S, Burmester GR, Sterry W, Worm M. Cutaneous side-effects in patients with rheumatic diseases during application of tumour necrosis factor-alpha antagonists. Br J Dermatol. 2007 Mar; 156(3):486-91

31. Sen ES, Morgan MJ, MacLeod R, Strike H, Hinchcliffe A, Dick AD, Muthusamy B, Ramanan AV. Cross sectional, qualitative thematic analysis of patient perspectives of disease impact in juvenile idiopathic arthritis-associated uveitis. Pediatr Rheumatol Online J. 2017;15(1):58

32. BSPAR and RCOphth Guidelines for screening for uveitis in juvenile idiopathic arthritis 2006 http://www.bspar.org.uk/downloads/clinical_ guidelines/BSPAR_guidelines_eye_screening_2006.pdf

33. Kadayifçilar S, Eldem B, Tumer B. Uveitis in childhood. J Pediatr Ophthalmol Strabismus. 2003;40(6):335-40.

Ready to submit your research? Choose BMC and benefit from:

- fast, convenient online submission

- thorough peer review by experienced researchers in your field

- rapid publication on acceptance

- support for research data, including large and complex data types

- gold Open Access which fosters wider collaboration and increased citations

- maximum visibility for your research: over $100 \mathrm{M}$ website views per year

At BMC, research is always in progress.

Learn more biomedcentral.com/submissions 